\title{
Evaluation of rifampicin and isoniazid susceptibility testing of Mycobacterium tuberculosis by a mycobacteriophage D29-based assay

\begin{abstract}
Correspondence
José A. Chauca

joch@hotmail.com
\end{abstract} \\ Received 11 March 2006 \\ Accepted 13 November 2006

\author{
José A. Chauca, ${ }^{1}$ Juan-Carlos Palomino ${ }^{2}$ and Humberto Guerra ${ }^{1}$ \\ ${ }^{1}$ Instituto de Medicina Tropical "Alexander von Humboldt", Universidad Peruana Cayetano \\ Heredia, PO Box 4314, Lima 100, Peru \\ ${ }^{2}$ Mycobacteriology Unit, Prince Leopold Institute of Tropical Medicine, Nationalestraat 155, \\ B-2000 Antwerp, Belgium
}

\section{INTRODUCTION}

Tuberculosis (TB) is an important worldwide public health problem, according to indicators of morbidity and mortality (World Health Organization, 2005). The World Health Organization has implemented a series of strategies, especially the Directly Observed Treatment Short Course (DOTS), seeking better control of the disease. The aim of DOTS is to ensure completion of effective antibiotic treatment based on rifampicin (RIF), isoniazid (INH), pyrazinamide and ethambutol (Iseman, 1998). This therapy has been designed to obtain a rapid cure of patients with TB and avoid the appearance of strains resistant to these antibiotics. Within the different patterns of resistance, multidrugresistant (MDR) strains of Mycobacterium tuberculosis, resistant to at least INH and RIF, constitute an important problem for TB control (Heifets \& Cangelosi, 1999; Watterson \& Drobniewski, 2000). Rapid detection of

Abbreviations: DST, drug susceptibility testing; INH, isoniazid; MDR, multidrug resistance/resistant; MYDBA, mycobacteriophage D29based assay; RIF, rifampicin; ROC, receiver operating characteristic; TB, tuberculosis. resistant strains is very important to restrict their dissemination in the population (Heifets \& Cangelosi, 1999). Conventional methods for drug susceptibility testing (DST) in TB are based on culture and growth of M. tuberculosis in drug-containing egg-based or agar culture media, which need long incubation periods to yield visible colonies (Heifets \& Cangelosi, 1999; Heifets, 1991). The BACTEC TB-460 system (Becton Dickinson) automated radiometric instrument and advances in the field of molecular biology have allowed reduction of the time required for DST of $M$. tuberculosis to first-line drugs (Tortoli et al., 2002; Watterson \& Drobniewski, 2000; Watterson et al., 1998). The high cost and requirement of sophisticated equipment make it impossible to routinely use such procedures in developing countries, where most of the TB patients are found (McNerney, 1999). New rapid tests based on mycobacteriophage D29 (bacteriophage able to infect most members of the genus Mycobacterium) are an attractive alternative (David et al., 1980b). These tests rely on the fact that the mycobacteriophage cycle will be completed only in viable host cells (mycobacteria); therefore, if $M$. tuberculosis is exposed to a mycobacteriophage, efficient replication of the virus would indirectly indicate the viability of the 
mycobacterium (David et al., 1980a, b; Hatfull, 1999, 2005). First exposing a strain of $M$. tuberculosis susceptible to RIF to a critical concentration of this drug and then infecting it with mycobacteriophage D29 will result in no phage replication; if a strain resistant to RIF is infected, the phage will continue its replication and produce bacterial lysis (Eltringham et al., 1999a; Galí et al., 2003; McNerney et al., 2000; Símboli et al., 2005). Since evidence of a lytic cycle depends on replication of the host bacterium, a rapidgrowing mycobacterium, Mycobacterium smegmatis, is used to reduce the turnaround time of drug susceptibility results (David et al., 1980a). Other drugs such as INH probably cannot interfere directly with phage replication, but their effect on susceptible mycobacteria will still make them incapable of producing new phage (Eltringham et al., 1999b; McNerney et al., 2000).

The purpose of this study was to evaluate the accuracy of a rapid susceptibility test based on mycobacteriophage D29 for DST of M. tuberculosis to RIF and INH. The accuracy of the test was defined as its capacity to identify true resistant and true susceptible strains of $M$. tuberculosis as determined by the standard proportion test.

\section{METHODS}

Mycobacterial strains. Ninety-three strains of M. tuberculosis (cultured from clinical specimens of Peruvian patients) from the strain collection of the Institute of Tropical Medicine Alexander von Humboldt of the Universidad Peruana Cayetano Heredia, Lima, Peru, were included in the study. The strains were identified by conventional biochemical methods (Kent \& Kubica, 1985). They were subcultured in Löwenstein-Jensen (LJ) medium and incubated for 3 weeks at $37^{\circ} \mathrm{C}$ before being tested. American Type Culture Collection (ATCC) reference strains ATCC 35838 resistant to RIF and ATCC 35822 resistant to INH were used as controls.

The mycobacteriophage D29-based assay (MYDBA). This assay was carried out following a modification of the procedure described by McNerney et al. (1998). INH and RIF (Sigma-Aldrich) solutions were prepared at concentrations of $1 \mathrm{mg} \mathrm{ml}^{-1}$ in distilled water and $10 \mathrm{mg} \mathrm{ml}^{-1}$ in methanol, respectively, filter-sterilized and kept frozen until used (Kent \& Kubica, 1985). The detection of strains resistant to RIF using the MYDBA was made by inoculating each strain in two tubes of Luria broth with $1 \mathrm{mM} \mathrm{CaCl}_{2}$ (LB-S), one containing $2 \mu \mathrm{g} \mathrm{RIF} \mathrm{ml}{ }^{-1}$ and the other no antibiotic. For INH the antibiotic tube contained $1 \mu \mathrm{g} \mathrm{ml}^{-1}$ of the drug. The tubes were incubated at $37^{\circ} \mathrm{C}$ for $24 \mathrm{~h}$ for RIF and $48 \mathrm{~h}$ for INH. The concentrations of antibiotics were determined by a checkerboard assay using the reference strains indicated. The bacteria were infected with mycobacteriophage D29 for $1.5 \mathrm{~h}$. Extracellular mycobacteriophage D29 was eliminated with $0.03 \mathrm{M}$ ferrous ammonium sulfate (FAS). FAS action was stopped by adding more LB-S to a 1:5 dilution. Then, $100 \mu \mathrm{l}$ was taken from each tube and inoculated in tubes containing $4 \mathrm{ml}$ molten agar at $45^{\circ} \mathrm{C}$ and $400 \mu \mathrm{l} \mathrm{M}$. smegmatis grown in Middlebrook 7H9 broth. The tubes were poured onto Petri dishes with $\mathrm{LB}$ agar plus $1 \mathrm{mM} \mathrm{CaCl}$. The Petri dishes were incubated for $24 \mathrm{~h}$ at $37^{\circ} \mathrm{C}$ and the number of infection plaques was counted. A strain was considered resistant if there were $10 \%$ or more plaques in the Petri dish from the drug-containing tube compared to the Petri dish from the control tube without antibiotic; a strain was considered susceptible if the number of plaques was less than $10 \%$ of those in the control dish.

Proportion method. All the strains were also tested by the proportion method on LJ medium, according to standard procedures, at concentrations of $0.2 \mu \mathrm{g} \mathrm{INH} \mathrm{ml}^{-1}$ and $40 \mu \mathrm{g} \mathrm{RIF} \mathrm{ml}^{-1}$ (Heifets, 1991).

Data analysis. Data analysis involved the use of receiver operating characteristic (ROC) curves and results for each drug under evaluation were interpreted in terms of sensitivity and specificity using the proportion method as the gold standard (Altman, 1991; Hanley \& McNeil, 1982; Shapiro, 1999; Swets, 1988). Predicted values were calculated by the Bayes theorem using published prevalence of resistant M. tuberculosis strains in Peru as an a priori probability (World Health Organization, 1997). The level of agreement between the mycobacteriophage D29-based assay and detection of MDR-TB strains with the proportion method was measured using the kappa $(\kappa)$ index of agreement (Altman, 1991). The calculations were made with SPSS v. 11.0.

\section{RESULTS AND DISCUSSION}

According to the proportion method, 43/93 (46.2\%) of the strains were resistant to RIF and INH (MDR strains), 3/93 $(3.2 \%)$ were susceptible to RIF and resistant to INH and the remaining 47/93 (50.5\%) were susceptible to both drugs. The agreement between the results obtained using the MYDBA and the proportion method is shown in Table 1. The discriminative capacity of the DST for RIF and INH using the MYDBA according to the area under the ROC curve (AUC) is shown in Fig. 1 and Fig. 2. The test for RIF shows a high ('excellent') exactitude with an AUC >0.99, while that for INH is 'good' with an AUC $>0.85$, indicating that it could be useful in some cases (depending on TB prevalence).

The sensitivity and specificity of the MYDBA, considering a cut-off of $90 \%$ of inhibition of the phage infection, as suggested by previous studies (Eltringham et al., 1999a), is shown in Table 1. The positive and negative predictive

Table 1. Sensitivity and specificity of the MYDBA in the susceptibility testing of 93 isolates of Mycobacterium tuberculosis to $\mathrm{RIF}$ and INH

MOP, proportion method.

\begin{tabular}{|c|c|c|c|c|c|c|}
\hline Antibiotic & $\begin{array}{l}\text { Susceptible, } \\
\text { both methods }\end{array}$ & $\begin{array}{l}\text { Susceptible, MOP } \\
\text { resistant, MYDBA }\end{array}$ & $\begin{array}{c}\text { Resistant, MOP } \\
\text { susceptible, MYDBA }\end{array}$ & $\begin{array}{l}\text { Resistant, } \\
\text { both methods }\end{array}$ & $\begin{array}{l}\text { Sensitivity } \\
(\%)\end{array}$ & $\begin{array}{c}\text { Specificity } \\
(\%)\end{array}$ \\
\hline INH & 38 & 9 & 9 & 37 & 80.4 & 80.8 \\
\hline
\end{tabular}




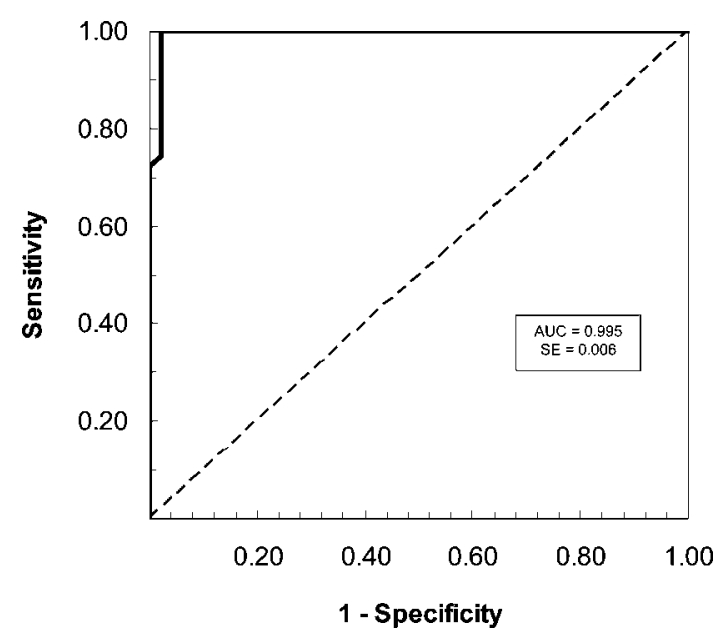

Fig. 1. Empirical ROC curve (-) for the susceptibility of $M$. tuberculosis $(n=93)$ to RIF using the MYDBA. The diagonal line (--) indicates a theoretical test that does not have discriminative capacity between resistant and susceptible strains. AUC, Area under curve; SE, standard error.

values for detection of resistance or susceptibility to RIF and INH are shown in Table 2. The agreement between the MYDBA for determining resistance to RIF and the detection of MDR-TB strains with the proportion method was very high $(\kappa$ index $=0.978 ; \mathrm{SE}=0.021)$. The results for INH using the mycobacteriophage D29 had a moderate agreement $(\kappa$ index $=0.548$; $\mathrm{SE}=0.087$ ).

There has been increasing interest in designing and improving tests based on mycobacteriophages since the first publication of Wilson et al. (1997) on the potential of mycobacteriophage D29 as a tool for the determination of

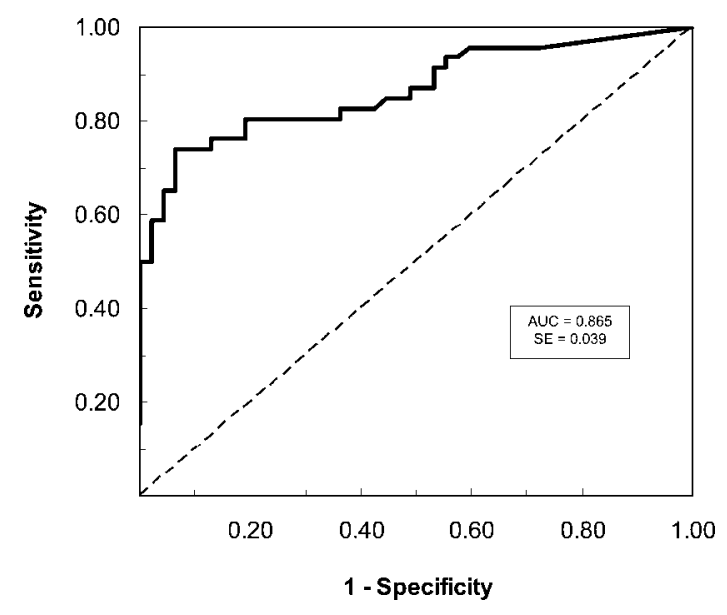

Fig. 2. Empirical ROC curve (-) for the susceptibility of $M$. tuberculosis $(n=93)$ to INH using the MYDBA. The diagonal line (--) represents a theoretical test that does not have discriminative capacity between resistant and susceptible strains. AUC, Area under curve; SE, standard error.
Table 2. Predictive values of the MYDBA in the susceptibility testing of Mycobacterium tuberculosis to RIF and INH

PPV, Positive predictive value; NPV, negative predictive value.

\begin{tabular}{|c|c|c|c|c|c|c|}
\hline & \multirow{2}{*}{ Patient } & \multirow{2}{*}{$\begin{array}{l}\text { Prevalence } \\
\qquad \%)^{*}\end{array}$} & \multicolumn{2}{|c|}{ MYDBA-RIF } & \multicolumn{2}{|c|}{ MYDBA-INH } \\
\hline & & & PPV & NPV & PPV & NPV \\
\hline \multirow{2}{*}{$\begin{array}{l}\text { RIF } \\
\text { resistance }\end{array}$} & New & 4 & 67.6 & 100 & - & - \\
\hline & $\begin{array}{c}\text { Previously } \\
\text { treated }\end{array}$ & 14.6 & 89.5 & 100 & - & - \\
\hline \multirow[t]{2}{*}{$\begin{array}{l}\text { INH } \\
\text { resistance }\end{array}$} & New & 9 & - & - & 29.3 & 97.7 \\
\hline & $\begin{array}{c}\text { Previously } \\
\text { treated }\end{array}$ & 16.2 & - & - & 44.7 & 95.5 \\
\hline
\end{tabular}

${ }^{*}$ World Health Organization (1997).

antibiotic susceptibility of M. tuberculosis (McNerney, 1999). Our results agree with those of other authors. Thus Símboli et al. (2005) have shown that their in-house mycobacteriophage D29 amplification assay for detecting RIF-resistant M. tuberculosis has a high performance $(100 \%$ sensitivity and $97.7 \%$ specificity). This performance may be explained by the key role of RNA polymerase in the transcription of the bacterial genome (host) and also in the efficient transcription of the phage genome and the generation of new phage progeny (Hatfull, 1999, 2005). The specific binding of RIF to RNA polymerase permanently inhibits its catalytic activity (David et al., 1980b; Heifets, 1991). Therefore, point mutations in the $r p o B$ gene, which encodes RNA polymerase, produce modifications of this enzyme, making it resistant to RIF inactivation and allowing phage multiplication.

An important aspect in the pattern of antibiotic susceptibility of $M$. tuberculosis is the association between the resistance to RIF and that to INH (World Health Organization, 1998). In this study, 43/43 (100\%) of the RIF-resistant strains were also resistant to $\mathrm{INH}$, in accordance with previous observations. Since RIF and INH are the most important drugs for TB treatment, RIF resistance could be an important marker, indicating that a patient would not benefit with the standard antituberculosis regimen, and requires the use of second-line drugs. Most RIF-resistant strains worldwide are also MDR, so the speed $(48 \mathrm{~h})$ of mycobacteriophage tests is a substantial advantage, allowing better therapeutic management of patients through rapid detection of MDR strains and reduction of the turnaround time for diagnosis. Faster, improved detection of MDR-TB strains coupled to an efficient patient management system would avoid their further dissemination through appropriate use of second-line drugs.

Simultaneous MYDBA determination of INH resistance will add information indicating, with good approximation, whether this drug could be used with second-line drugs or not. 
There were instances where the MYDBA and the proportion method gave discrepant results for INH susceptibility. There must be mechanistic reasons for this discrepancy, which was reproducible in the same strains. There are discrepant results between the D29-based and the conventional proportion method; Galí et al. (2006) have also noted this, and suggested that the sensitivity of phage methods in detecting INH resistance depends on the resistance level of the isolates. An evaluation of our strains with the Microplate Alamar Blue Assay has shown that five of the nine discrepant resistant strains had MICs $\leqslant 0.5 \mu \mathrm{g} \mathrm{ml}^{-1}$, while in a random sample of 34 resistant strains (those resistant to INH according to both the MYDBA and proportion method) only eight had MICs $\leqslant 0.5 \mu \mathrm{g} \mathrm{ml}^{-1}$. The INH inhibits mycolic acid synthesis (major lipid component of the mycobacterial cell wall skeleton), both in whole cells and in cell extracts (Bardou et al., 1996). Therefore, the activity of INH on the lytic cycle of mycobacteriophage is indirect. Bardou et al. (1996) have shown that an early effect of INH on the ultrastructure of mycobacteria was an alteration at the bacterial poles accompanied by a release of proteins from the poles into the extracellular medium. They have suggested that this release of extracellular proteins is proportional to the concentration of INH necessary to inhibit mycolate biosynthesis (Bardou et al., 1996). This could explain some of the discrepant results observed. Current 'classical' DST methods, including the proportion method, are seldom formally contrasted with in vivo treatment results, especially with controlled animal experiments. Testing of antimicrobial sensitivity tests using animal models seems entirely warranted to determine the significance of the discrepant results found between the two in vitro methods here evaluated.

Future research should aim at further simplification of candidate DS tests with less laboratory manipulation steps. New methods could measure mycobacteriophage activity quantitatively through metabolites released during bacterial lysis (e.g. ATP or specific enzymes). Recent advances in molecular biology and better knowledge of Mycobacteriummycobacteriophage interactions could result in the design of various receptor-specific phages, which would be capable of species determination within the genus Mycobacterium.

In conclusion, the MYDBA for RIF due to its low cost and high diagnostic accuracy in comparison to the proportion method is ready to become a useful tool in the therapeutic handling of patients with TB. The MYDBA for INH requires the validation of its accuracy as compared with in vivo methods, but the rapid availability of its results overshadows its theoretical disadvantage.

\section{ACKNOWLEDGEMENTS}

The authors wish to thank Dr Françoise Portaels for her support and that of the Mycobacterial Unit, Institute of Tropical Medicine, Antwerp 2000, expressed in many ways, and Dr Ruth McNerney from the London School of Hygiene and Tropical Medicine for her advice and the gift of the phage D29 and the Mycobacterium smegmatis strain used throughout the experiments. The study was supported by the Directorate-General for Development Cooperation of the Belgian Government (DGDC); project 95501.

\section{REFERENCES}

Altman, D. (1991). Some common problems in medical research. In Practical Statistics for Medical Research, pp. 396-439. Edited by D. G. Altman. London: Chapman \& Hall.

Bardou, F., Quémard, A., Dupont, M., Horn, C., Marchal, G. \& Daffé, M. (1996). Effects of isoniazid on ultrastructure of Mycobacterium aurum and Mycobacterium tuberculosis and on production of secreted proteins. Antimicrob Agents Chemother 40, 2459-2467.

David, H., Clavel, S. \& Clement, F. (1980a). Adsorption and growth of the bacteriophage D29 in selected mycobacteria. Ann Virol (Inst Pasteur) 131, 167-184.

David, H., Clavel, S., Clement, F. \& Moniz-Pereira, J. (1980b). Effects of antituberculosis and antileprosy drugs on mycobacteriophage D29 growth. Antimicrob Agents Chemother 18, 357-359.

Eltringham, I., Drobniewski, F. A., Mangan, J. A., Butcher, P. D. \& Wilson, S. M. (1999a). Evaluation of reverse transcription-PCR and a bacteriophage-based assay for rapid phenotypic detection of rifampin resistance in clinical isolates of Mycobacterium tuberculosis. J Clin Microbiol 37, 3524-3527.

Eltringham, I., Wilson, S. \& Drobniewski, F. (1999b). Evaluation of a bacteriophage-based assay (phage amplified biologically assay) as rapid screen for resistance to isoniazid, ethambutol, streptomycin, pyrazinamide, and ciprofloxacin among clinical isolates of Mycobacterium tuberculosis. J Clin Microbiol 37, 3528-3532.

Gali, N., Dominguez, J., Blanco, S., Prat, C., Quesada, M., Matas, L. \& Auxina, V. (2003). Utility of an in-house mycobacteriophage-based assay for rapid detection of rifampin resistance in Mycobacterium tuberculosis clinical isolates. J Clin Microbiol 41, 2647-2649.

Galí, N., Domínguez, J., Blanco, S., Prat, C., Alcaide, F., Coll, P. \& Ausina, V. (2006). Use of a mycobacteriophage-based assay for rapid assessment of susceptibilities of Mycobacterium tuberculosis isolates to isoniazid and influence of resistance level on assay performance. J Clin Microbiol 44, 201-205.

Hanley, J. A. \& McNeil, B. J. (1982). The meaning and use of the area under a receiver operating characteristic (ROC) curve. Radiology 143, 29-36.

Hatfull, G. (1999). Mycobacteriophage. In Mycobacteria - Molecular Biology and Virulence, pp. 38-58. Edited by C. Ratledge \& J. Dale. London: Blackwell.

Hatfull, G. (2005). Mycobacteriophages: pathogenesis and applications. In Phages: Their Role in Bacterial Pathogenesis and Biotechnology, pp. 238-255. Edited by M. Waldor, D. Friedman \& S. Adhya. Washington, DC: American Society for Microbiology.

Heifets, L. (editor) (1991). Drug susceptibility test in the management of chemotherapy of tuberculosis. In Drug Susceptibility in the Chemotherapy of Mycobacterial Infections, pp. 90-115. Florida: CRC Press.

Heifets, L. \& Cangelosi, G. (1999). Drug susceptibility testing of Mycobacterium tuberculosis: a neglected problem at the turn of the century. Int J Tuberc Lung Dis 3, 564-581.

Iseman, M. D. (1998). MDR-TB and the developing world - a problem no longer to be ignored: the WHO announces 'DOTS Plus' strategy. Int J Tuberc Lung Dis 2, 867.

Kent, P. T. \& Kubica, G. P. (1985). Public Health Mycobacteriology: a Guide for the Level III Laboratory. Atlanta, GA: US Department of Health and Human Services, Centers for Disease Control. 
McNerney, R. (1999). TB: the return of the phage. A review of fifty years of mycobacteriophage research. Int J Tuberc Lung Dis 3, 179-184.

McNerney, R., Wilson, S., Sidhu, A., Harley, V., Al-Suwanidi, Z., Nye, P., Parish, T. \& Stoker, N. (1998). Inactivation of mycobacteriophage D29 using ferrous ammonium sulphate as a tool for the detection of viable Mycobacterium smegmatis and M. tuberculosis. Res Microbiol 149, 487-495.

McNerney, R., Kiepiela, P., Bishop, K., Nye, P. M. \& Stoker, N. G. (2000). Rapid screening of Mycobacterium tuberculosis for susceptibility to rifampicin and streptomycin. Int J Tuberc Lung Dis 4, 69-75.

Shapiro, D. (1999). The interpretation of diagnostic tests. Stat Methods Med Res 8, 113-134.

Simboli, N., Takiff, H., McNerney, R., Lopez, B., Martin, A., Palomino, J. C., Barrera, L. \& Ritacco, V. (2005). In-house phage amplification assay is a sound alternative for detecting rifampin-resistant Mycobacterium tuberculosis in low-resource settings. Antimicrob Agents Chemother 49, 425-427.

Swets, J. (1988). Measuring the accuracy of diagnostic systems. Science 240, 1285-1293.

Tortoli, E., Benedetti, M., Fontanelli, A. \& Simonetti, M. (2002). Evaluation of automated BACTEC MGIT 960 system for testing susceptibility of Mycobacterium tuberculosis to four major antituberculous drugs: comparison with the radiometric BACTEC $460 \mathrm{~TB}$ method and the agar plate method of proportion. J Clin Microbiol 40, 607-610.

Watterson, S. \& Drobniewski, F. (2000). Modern laboratory diagnosis of mycobacterial infections. J Clin Pathol 53, 727-732.

Watterson, S., Wilson, S., Yates, W. \& Drobniewski, F. (1998). Comparison of three molecular assays for rapid detection of rifampin resistance in Mycobacterium tuberculosis. J Clin Microbiol 36, 1969-1973.

Wilson, S., Al-Suwaidi, Z., McNerney, R., Porter, J. \& Drobniewski, F. (1997). Evaluation of a new rapid bacteriophage-based method for the drug susceptibility testing of Mycobacterium tuberculosis. Nat Med 34, 465-468.

World Health Organization (1997). Global Tuberculosis Programme. Anti-Tuberculosis Drug Resistance in the World. The WHO/IUATLD Global Project on Anti-Tuberculosis Drug Resistance Surveillance 1994-1997. Annex 2 - Individual Country Profiles. WHO/TB/97.229. Geneva: World Health Organization.

World Health Organization (1998). Guidelines for surveillance of drug resistance in tuberculosis. Int J Tuberc Lung Dis 2, 72-89.

World Health Organization (2005). WHO Report 2005. Global Tuberculosis Control - Surveillance, Planning, Financing. WHO/ HTM/TB/2005.349. Geneva: World Health Organization. 